\title{
ChemComm
}

\section{Oxovanadium(v)-induced diastereoselective oxidative homocoupling of boron enolates $\dagger$}

Cite this: Chem. Commun., 2014 50, 2279

Received 19th December 2013, Accepted 30th December 2013

DOI: $10.1039 / c 3 c c 49624 d$

www.rsc.org/chemcomm

\author{
Toru Amaya, ${ }^{a}$ Takaya Masuda, ${ }^{a}$ Yusuke Maegawa ${ }^{a}$ and Toshikazu Hirao*ab
}

\begin{abstract}
Oxovanadium(v)-induced $d l$-selective oxidative coupling of $(Z)$-boron enolate was demonstrated to give the corresponding 2,3-disubstituted 1,4-diketone in a good yield. High selectivity (up to $94: 6$ ) was attained when the reaction was performed with $\mathrm{VO}(\mathrm{OPr}-\mathrm{i})_{2} \mathrm{Cl}$ at $-30{ }^{\circ} \mathrm{C}$.
\end{abstract}

Oxidative coupling of enolates can directly afford a 1,4-dicarbonyl skeleton. This is one of the most straightforward approaches to construct such a skeleton, which is often found in natural products, medicinal compounds, organic materials, and their synthetic intermediates. So far, a lot of research has been conducted to develop this type of oxidative coupling reaction. ${ }^{1}$

The reaction focused on here is intermolecular oxidative homocoupling of ketone enolates. This kind of coupling reaction has been investigated since 1974, and the combination of various oxidants and enolates have been investigated to date. ${ }^{2}$ However, there is only limited information on the diastereoselective coupling reaction. ${ }^{3}$ This contrasts sharply with the oxidative homocoupling reaction of acyl enolates, in which the chiral auxiliaries can be utilized. ${ }^{4}$ As a special case, the enolate of $(1 R)$-camphor was exhibited to undergo the stereoselective oxidative homocoupling. ${ }^{3 c}$ Recently, chiral cyclohexenones were revealed to be oxidatively coupled to afford the corresponding 1,4-diketones diastereoselectively. ${ }^{3 e}$ As a general strategy, the diastereoselective oxidative coupling of the metalated $(S)$-(-)-1-amino-2-methoxymethylpyrrolidine (SAMP) or its $(R)$-isomer, RAMP hydrazone, with iodine was reported, ${ }^{3 a}$ where the oxidative cleavage of the $\mathrm{N}-\mathrm{N}$ bond of the hydrazone using ozone is required to obtain the corresponding ketones, and the overall yields remain low to moderate. Another approach for the diastereoselective synthesis includes the intramolecular oxidative

\footnotetext{
${ }^{a}$ Department of Applied Chemistry, Graduate School of Engineering, Osaka University, Yamada-oka, Suita, Osaka 565-0871, Japan. E-mail: hirao@chem.eng.osaka-u.ac.jp

${ }^{b}$ JST, ACT-C, 4-1-8 Honcho, Kawaguchi, Saitama 332-0012, Japan

$\dagger$ Electronic supplementary information (ESI) available: Detailed experimental procedures, and compounds characterization, including ${ }^{1} \mathrm{H}$ and ${ }^{13} \mathrm{C}$ NMR spectra, and X-ray crystallographic analysis for $d l-3 \mathbf{d}$ and $d l-3 e$. CCDC 969200 and 969201. For ESI and crystallographic data in CIF or other electronic format see DOI: $10.1039 / \mathrm{c} 3 \mathrm{cc} 49624 \mathrm{~d}$
}

coupling using a traceless tether such as titanium and silicon for two ketone enolates, although the tethered enolate intermediate requires a synthetic step for its preparation. ${ }^{1 b, 3 b, d}$

Boron enolates have been utilized in a variety of organic syntheses that include a stereoselective aldol reaction. ${ }^{5}$ Nevertheless, boron enolates have not been used for the oxidative homocoupling reaction to the best of our knowledge. In the present study, boron enolates are focused on from this point of view. So far, we have studied the oxidative carbon-carbon bond formation induced by oxovanadium(v) compounds, ${ }^{6}$ including the oxidative homo- and cross-coupling of silyl enol ethers to form the corresponding 1,4-diketones. ${ }^{2 j}$ Here, we report the oxidative homocoupling of boron enolates using oxovanadium(v) compounds. Notably, a high yield with high $d l$-selectivity was exhibited.

Boron enolates were prepared via 1,4-hydroboration of enones (Scheme 1). ${ }^{7}$ This reaction was monitored by ${ }^{1} \mathrm{H}$ NMR spectroscopy to check the conversion and geometric configuration. To a $\mathrm{CDCl}_{3}$ solution of enone 1a the THF solution of 9-borabicyclo[3.3.1]nonane(9-BBN) was added in the presence of MS4A at room temperature. After $2 \mathrm{~h}$, the peaks for enone 1a disappeared in the ${ }^{1} \mathrm{H}$ NMR spectrum. Instead, a characteristic quartet peak appeared at $5.55 \mathrm{ppm}$, assignable to the vinyl proton in boron enolate $2 \mathrm{a}$. This enolate was formed as a sole diastereomer almost quantitatively.

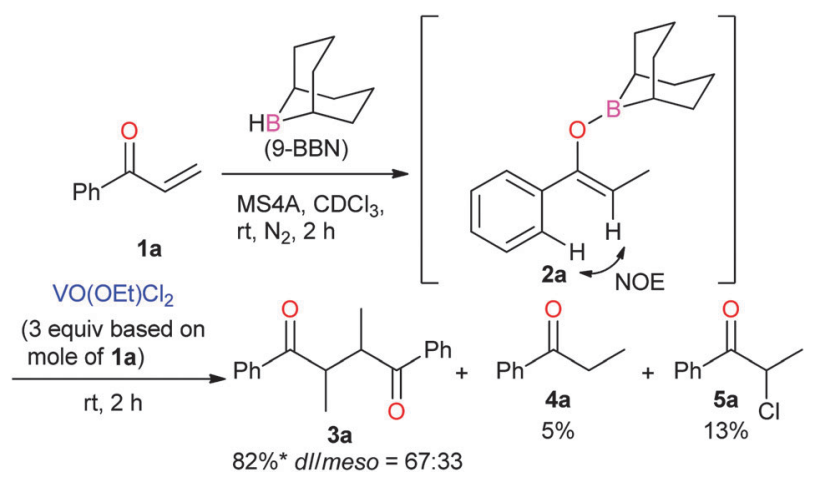

Scheme 1 Formation of boron enolate $2 \mathbf{a}$ and the oxidative homocoupling with $\mathrm{VO}(\mathrm{OEt}) \mathrm{Cl}_{2}$ * ${ }^{*}$ Yield of $3 \mathrm{a}=($ mole of $3 \mathrm{a}) \times 2 /($ mole of $1 \mathrm{a}) \times 100$. 
Its stereo-configuration was determined to be (Z)-form based on the observation of a NOE between the ortho-protons of the phenyl group and vinyl proton. To the thus-obtained boron enolate three molar equivalents of $\mathrm{VO}(\mathrm{OEt}) \mathrm{Cl}_{2}$ were added at room temperature (Scheme 1). After $2 \mathrm{~h}$, the mixture was subjected to aqueous work-up. The desired homocoupled product 3a was obtained in $82 \%$ yield, where the diastereomeric ratio (dl/meso) was $67: 33{ }^{8}$ Propiophenone (4a) and 2-chloropropiophenone (5a) were observed as side products in this reaction ( $5 \%$ and $13 \%$ yields, respectively). The yield of 3a after a 5-minute reaction was comparable to that after $2 \mathrm{~h}$ (83\%, Table 1, entry 2), indicating that the reaction proceeded fast. Lowering the amount of the oxidant to one molar equivalent caused the yield of $3 \mathbf{a}$ to decrease a little (76\%, Table 1 , entry 3). In this entry, ${ }^{51} \mathrm{~V}$ NMR was measured after the reaction. Consequently, the characteristic peak at $-294 \mathrm{ppm}$ for $\mathrm{VO}(\mathrm{OEt}) \mathrm{Cl}_{2}$ disappeared to lead to a vanadium(Iv) species (Fig. 1). Further decreasing the amount of the oxidant (0.5 molar equivalents) yielded $\mathbf{3 a}$ in $47 \%$ yield. These results show that the oxovanadium(v) oxidant formally works as a one-electron oxidant toward the boron enolate.

Various oxovanadium(v) oxidants were investigated, as summarised in Table 2. The alkoxy ligands in oxovanadium(v) compounds are known to affect the oxidation reaction. Their oxidation capability usually decreases with the increasing number of alkoxy groups in the complex. Reversely, it increases with the increasing number of the chlorides. The reaction with

Table 1 Investigation of equivalents of $\mathrm{VO}(\mathrm{OEt}) \mathrm{Cl}_{2}$ and reaction time in the oxidative homocoupling reaction ${ }^{a}$

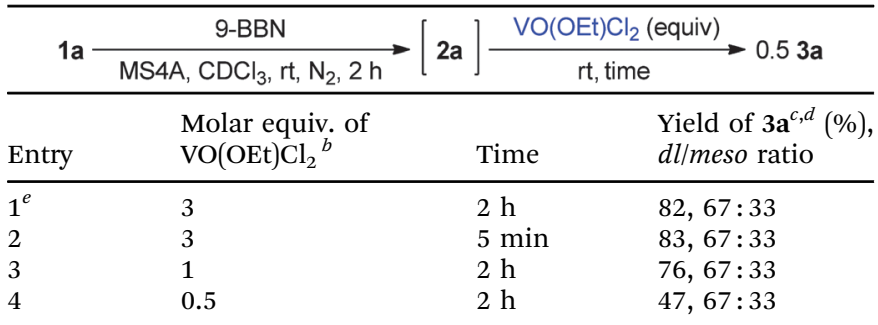

${ }^{a}$ NMR tube experiments. ${ }^{b}$ Based on mole of 1a. ${ }^{c 1} \mathrm{H}$ NMR yield. ${ }^{d}$ Yield $=($ mole of 3a $) \times 2 /($ mole of 1a $) \times 100 .{ }^{e}$ Same as the result in Scheme 1.

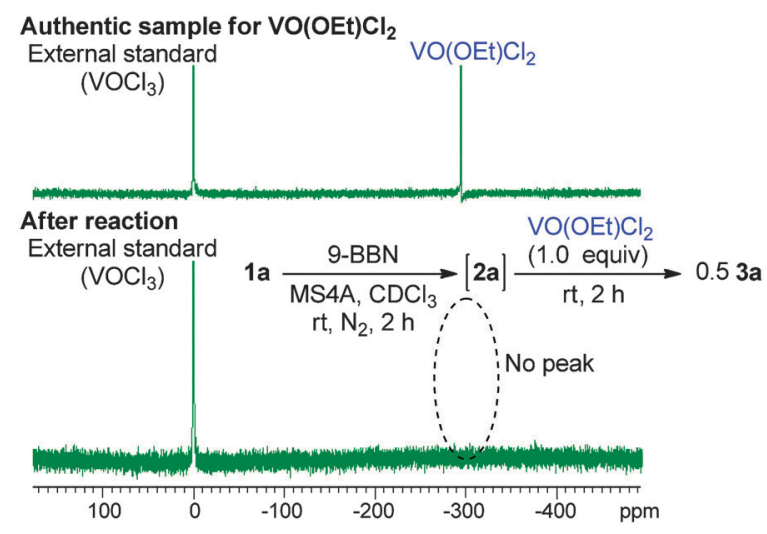

Fig. $1{ }^{51} \mathrm{~V}$ NMR spectra of the authentic sample of $\mathrm{VO}(\mathrm{OEt}) \mathrm{Cl}_{2}$ and after the reaction.
Table 2 Investigation of oxidant in the oxidative homocoupling reaction ${ }^{a}$

\begin{tabular}{|c|c|c|c|c|}
\hline \multirow{2}{*}{$\begin{array}{r}\text { 1a } \\
\text { Entry }\end{array}$} & \multicolumn{2}{|l|}{$\frac{9-\mathrm{BBN}}{\mathrm{CDCl}{ }_{3}, \mathrm{rt},}$} & \multicolumn{2}{|c|}{$\begin{array}{c}\text { oxidant } \\
\underset{\text { temperature, time }}{(3 \text { equiv based on mole of } 1 \mathrm{a})}\end{array} 0.53 \mathrm{a}$} \\
\hline & Oxidant & $\begin{array}{l}\text { Time } \\
\text { (h) }\end{array}$ & $\begin{array}{l}\text { Temperature } \\
\left({ }^{\circ} \mathrm{C}\right)\end{array}$ & $\begin{array}{l}\text { Yield of } 3 \mathbf{a}^{b, c}(\%), \\
\text { dl/meso ratio }\end{array}$ \\
\hline $1^{d}$ & $\mathrm{VO}(\mathrm{OEt}) \mathrm{Cl}_{2}$ & 0.5 & $\mathrm{rt}$ & $88,67: 33$ \\
\hline 2 & $\mathrm{VO}(\mathrm{OPr}-\mathrm{i})_{2} \mathrm{Cl}$ & 0.5 & $\mathrm{rt}$ & $78,80: 20$ \\
\hline 3 & $\mathrm{VO}(\mathrm{OPr}-\mathrm{i})_{2} \mathrm{Cl}$ & 0.5 & -30 & $76,92: 8$ \\
\hline 4 & $\mathrm{VO}(\mathrm{OPr}-\mathrm{i})_{2} \mathrm{Cl}$ & 19 & -30 & $96,94: 6$ \\
\hline $5^{e}$ & $\mathrm{VO}(\mathrm{OPr}-\mathrm{i})_{2} \mathrm{Cl}$ & 24 & -40 & $93 \stackrel{f}{f}_{86: 14}$ \\
\hline 6 & $\mathrm{VO}(\mathrm{OPr}-\mathrm{i})_{3}$ & 0.5 & $\mathrm{rt}$ & Trace \\
\hline 7 & $\mathrm{FeCl}_{3}$ & 19 & -30 & 0 \\
\hline 8 & $\mathrm{CuCl}_{2}$ & 19 & -30 & 0 \\
\hline 9 & CAN & 19 & -30 & $53,53: 47$ \\
\hline
\end{tabular}

${ }^{a}$ NMR tube experiments. ${ }^{b}{ }^{1} \mathrm{H}$ NMR yield. ${ }^{c}$ Yield $=($ mole of $3 a) \times$ $2 /($ mole of $1 \mathrm{a}) \times 100 .{ }^{d}$ Same as the result in Scheme $1 .{ }^{e} 100 \mathrm{mg}$ scale reaction. ${ }^{f}$ Isolated yield.

$\mathrm{VO}(\mathrm{OPr}-\mathrm{i})_{2} \mathrm{Cl}$ resulted in $3 \mathrm{a}$ in $78 \%$ yield with a $d / /$ meso ratio of $80: 20$ (Table 2, entry 2), where the diastereoselectivity is higher as compared to that of $\mathrm{VO}(\mathrm{OEt}) \mathrm{Cl}_{2}$ although the yield is a little lower than that of $\mathrm{VO}(\mathrm{OEt}) \mathrm{Cl}_{2}$. A lower temperature $\left(-30{ }^{\circ} \mathrm{C}\right)$ increased diastereoselectivity (Table 2, entry 3). Finally, a satisfactory yield and diastereoselectivity was obtained at $-30{ }^{\circ} \mathrm{C}$ for $19 \mathrm{~h}(96 \%, d l / m e s o=94: 6$, Table 2 , entry 4$)$, although a scale-up reaction (100 $\mathrm{mg}$ scale) slightly decreased the selectivity even at $-40{ }^{\circ} \mathrm{C}$ (Table 2 , entry 5 ). These reaction conditions were used for the following investigation as optimized conditions. On the other hand, $\mathrm{VO}(\mathrm{OPr}-\mathrm{i})_{3}$ did not induce the oxidative coupling due to the lower oxidation capability (Table 2, entry 6). Other oxidants such as $\mathrm{FeCl}_{3}$ and $\mathrm{CuCl}_{2}$ did not induce the oxidative homocoupling (Table 2, entries 7 and 8). In the case of $\left[\mathrm{Ce}\left(\mathrm{NO}_{3}\right)_{6}\right]\left(\mathrm{NH}_{4}\right)_{2}(\mathrm{CAN})$ as an oxidant, 3a was obtained in $53 \%$ yield with a low $\mathrm{dl} /$ meso selectivity.

Table 3 shows the scope of the substrates in the oxidative homocoupling using $\mathrm{VO}(\mathrm{OPr}-\mathrm{i})_{2} \mathrm{Cl}$ as an oxidant. All of enones 1 used here were transformed to the corresponding boron enolate stereoselectively. Various $p$-substitutions of the phenyl group in the boron enolates 1b-f were investigated. Me-, TBSO-, F-, Cl-, and $\mathrm{CF}_{3}$-groups were tolerated without the substitution effect to give the corresponding homocoupling products in high yields with high $d l$-selectivity (Table 3 , entries $1-5) .{ }^{9 a-e}$ Instead of the phenyl group, the cyclohexyl group as an example for an aliphatic substrate underwent the homocoupling in $97 \%$ yield with a $d l /$ meso selectivity ratio of $77: 23$ (Table 3 , entry 6$).{ }^{9 e}$ In the case of $(E)$-chalcone $(\mathbf{1 h})$, the diastereoselectivity was lower although the yield was high (Table 3 , entry 7 ). ${ }^{8}$

Considering the stereoselectivity based on the steric repulsion between the enolates, the $d l$-product is favorable in a chelation model and unfavorable in the non-chelation model (see Scheme S1 in the ESI $\dagger$ ) as Schmittel and co-workers also discussed the related reaction mechanism in the intramolecular oxidative homocoupling reaction of ketone enolates. ${ }^{3 b}$ Oxovanadium alkoxide compounds are known to self-assemble to form a dimer, ${ }^{10}$ so that the observed $d l$-selectivity may be accounted for by the intramolecular coupling in the dimer via the formation of the vanadium enolate species. A similar chelation model was also 
Table 3 Substrate scope in the oxidative homocoupling reaction ${ }^{a}$

(3 equiv based on mole of 1$)$
Entry

${ }^{a}$ NMR tube experiments. ${ }^{b}{ }^{1} \mathrm{H}$ NMR yield. ${ }^{c}$ Yield $=($ mole of 3$) \times$ $2 /($ mole of 1$) \times 100$.

presented in the oxidative homocoupling of ester enolates using $\mathrm{TiCl}_{4}$ to explain the $d l$-selectivity. ${ }^{11}$

In conclusion, $d l$-selective oxidative coupling of $(Z)$-boron enolate was demonstrated to give the corresponding 2,3disubstituted 1,4-diketone in a high yield. (Z)-boron enolate was prepared by 1,4-hydroboration of the enone, and it was used for the oxidative coupling reaction in one pot. Stereoselectivity strongly depended on the oxovanadium(v) oxidant and reaction temperature. High selectivity (up to $94: 6$ ) was attained when the reaction took place with $\mathrm{VO}(\mathrm{OPr}-\mathrm{i})_{2} \mathrm{Cl}$ at $-30{ }^{\circ} \mathrm{C}$. The mechanistic study and synthetic application are now underway.

This work was supported by JST, ACT-C (Japan). Thanks are due to Nichia corporation for the donation of $\mathrm{VO}(\mathrm{OPr}-\mathrm{i})_{3}$ and $\mathrm{VO}(\mathrm{OEt}) \mathrm{Cl}_{2}$.

\section{Notes and references}

1 For reviews and accounts: (a) A. G. Csákÿ and J. Plumet, Chem. Soc. Rev., 2001, 30, 313-320; (b) M. Schmittel and A. Haeuseler, J. Organomet. Chem., 2002, 661, 169-179; (c) C. S. Yeung and V. M. Dong, Chem. Rev., 2011, 111, 1215-1292; (d) F. Guo, M. D. Clift and R. J. Thomson, Eur. J. Org. Chem., 2012, 4881-4896.

2 (a) R. M. Dessau and E. I. Heiba, J. Org. Chem., 1974, 39, 3457-3459; (b) Y. Ito, T. Konoike and T. Saegusa, J. Am. Chem. Soc., 1975, 97, 649-651; (c) Y. Ito, T. Konoike and T. Saegusa, J. Am. Chem. Soc., 1975, 97, 2912-2914; (d) Y. Ito, T. Konoike, T. Harada and T. Saegusa, J. Am. Chem. Soc., 1977, 99, 1487-1493; (e) Y. Kobayashi, T. Taguchi and E. Tokuno, Tetrahedron Lett., 1977, 18, 3741-3742; $(f)$ Y. Kobayashi, T. Taguchi, T. Morikawa, E. Tokuno and S. Sekiguchi, Chem. Pharm.
Bull., 1980, 28, 262-267; $(g)$ R. H. Frazier Jr. and R. L. Harlow, J. Org. Chem., 1980, 45, 5408-5411; (h) E. Baciocchi, A. Casu and R. Ruzziconi, Tetrahedron Lett., 1989, 30, 3707-3710; (i) K. Narasaka, T. Okauchi, K. Tanaka and M. Murakami, Chem. Lett., 1992, 2099-2102; $(j)$ T. Fujii, T. Hirao and Y. Ohshiro, Tetrahedron Lett., 1992, 33, 5823-5826; (k) K. Ryter and T. Livinghouse, J. Am. Chem. Soc., 1998, 120, 2658-2659; (l) M. D. Clift, C. N. Taylor and R. J. Thomson, Org. Lett., 2007, 9, 4667-4669; $(m)$ M. D. Clift and R. J. Thomson, J. Am. Chem. Soc., 2009, 131, 14579-14583; (n) B. M. Casey and R. A. Flowers II, J. Am. Chem. Soc., 2011, 133, 11492-11495; (o) Y. Yasu, T. Koike and M. Akita, Chem. Commun., 2012, 48, 5355-5357; (p) H.-Q. Do, H. Tran-Vu and O. Daugulis, Organometallics, 2012, 31, 7816-7818.

3 (a) D. Enders, P. Müller and D. Klein, Synlett, 1998, 43-44; (b) M. Schmittel, A. Burghart, W. Malisch, J. Reising and R. Söllner, J. Org. Chem., 1998, 63, 396-400; (c) J. McNulty, M. J. Millar, G. Bernardinelli and C. W. Jefford, J. Org. Chem., 1999, 64, 5312-5314; (d) C. T. Avetta Jr., L. C. Konkol, C. N. Taylor, K. C. Dugan, C. L. Stern and R. J. Thomson, Org. Lett., 2008, 10, 5621-5624; (e) F. Guo, L. C. Konkol and R. J. Thomson, J. Am. Chem. Soc., 2011, 133, 18-20.

4 (a) N. A. Porter, Q. Su, J. J. Harp, I. J. Rosenstein and A. T. McPhail, Tetrahedron Lett., 1993, 34, 4457-4460; (b) N. Kise, K. Tokioka, Y. Aoyama and Y. Matsumura, J. Org. Chem., 1995, 60, 1100-1101; (c) T. Langer, M. Illich and G. Helmchen, Tetrahedron Lett., 1995, 36, 4409-4412; (d) T. Langer, M. Illich and G. Helmchen, Synlett, 1996, 1137-1139; (e) N. Kise, K. Kumada, Y. Terao and N. Ueda, Tetrahedron, 1998, 54, 2697-2708.

5 (a) B. M. Kim, S. F. Williams and S. Masamune, in Comprehensive Organic Synthesis, ed. B. M. Trost and I. Fleming, Pergamon Press, New York, 1991, vol. 2, pp. 239-275; (b) C. J. Cowden and I. Paterson, Org. React., 1997, 51, 1-200; (c) T. Mukaiyama and J.-I. Matsuo, in Modern Aldol Reactions, ed. R. Mahrwald, Wiley-VCH, Weinheim, Germany, 2004, ch. 3, vol. 1.

6 (a) T. Hirao, T. Fujii and Y. Ohshiro, Tetrahedron, 1994, 50, 10207-10214; (b) T. Ishikawa, A. Ogawa and T. Hirao, Organometallics, 1998, 17, 5713-5716; (c) T. Ishikawa, A. Ogawa and T. Hirao, J. Am. Chem. Soc., 1998, 120, 5124-5125; (d) T. Ishikawa, S. Nonaka, A. Ogawa and T. Hirao, Chem. Commun., 1998, 1209-1210; (e) T. Ishikawa, A. Ogawa and T. Hirao, J. Organomet. Chem., 1999, 575, 76-79; $(f)$ T. Hirao, T. Takada and A. Ogawa, J. Org. Chem., 2000, 65, 1511-1515; $(g)$ T. Hirao, T. Takada and H. Sakurai, Org. Lett., 2000, 2, 3659-3661; (h) T. Takada, H. Sakurai and T. Hirao, J. Org. Chem., 2001, 66, 300-302; (i) H. Mizuno, H. Sakurai, T. Amaya and T. Hirao, Chem. Commun., 2006, 5042-5044; $(j)$ T. Amaya, Y. Tsukamura and T. Hirao, Adv. Synth. Catal., 2009, 351, 1025-1028.

7 Y. Matsumoto and T. Hayashi, Synlett, 1991, 349-350.

8 The diastereomeric ratio ( $d l /$ meso $)$ was determined by ${ }^{1} \mathrm{H}$ NMR. The assignment for $d l$ and meso compounds was according to the following reference: S. E. Drewes, C. J. Hogan, P. T. Kaye and G. H. P. Roos, J. Chem. Soc., Perkin Trans. 1, 1989, 1585-1591.

9 The diastereomeric ratio $(\mathrm{dl} / \mathrm{meso})$ was determined by ${ }^{1} \mathrm{H}$ NMR. The assignment for $d l$ and meso compounds was performed as follows: (a) For 3b: H. Ikeda, T. Takasaki, Y. Takahashi, A. Konno, M. Matsumoto, Y. Hoshi, T. Aoki, T. Suzuki, J. L. Goodman and T. Miyashi, J. Org. Chem., 1999, 64, 1640-1649; $(b)$ For 3c: S. G. A. Moinuddin, S. Hishiyama, M.-H. Cho, L. B. Davin and N. G. Lewis, Org. Biomol. Chem., 2003, 1, 2307-2313; (c) For 3d: the $d l$-isomer was determined with X-ray crystallographic analysis (CCDC-969201), see ESI $\dagger$; $(d)$ For 3e: the $d l$-isomer was determined with X-ray crystallographic analysis (CCDC-969200), see ESI $\dagger$; $(e)$ For 3f and 3g: although the assignments could not be confirmed, they are predicted according to the tendency of ${ }^{1} \mathrm{H}$ NMR spectra for $3 \mathbf{b}-3 \mathbf{e}$, and $\mathbf{3 h}$.

10 C. N. Caughlan, H. M. Smith and K. Watenpaugh, Inorg. Chem., 1966, 5, 2131-2134.

11 Y. Matsumura, M. Nishimura, H. Hiu, M. Watanabe and N. Kise, J. Org. Chem., 1996, 61, 2809-2812. 